\title{
Role of transpiration in arsenic accumulation of hyperaccumulator Pteris vittata $\mathrm{L}$.
}

\author{
Xiao-ming Wan ${ }^{1} \cdot$ Mei Lei $^{1} \cdot$ Tong-bin Chen ${ }^{1}$. \\ Jun-xing Yang ${ }^{1} \cdot$ Hong-tao Liu ${ }^{1} \cdot$ Yang Chen ${ }^{1}$
}

Received: 15 December 2014 / Accepted: 18 May 2015 /Published online: 18 June 2015

(C) Springer-Verlag Berlin Heidelberg 2015

\begin{abstract}
Mechanisms of Pteris vittata L. to hyperaccumulate arsenic (As), especially the efficient translocation of As from rhizoids to fronds, are not clear yet. The present study aims to investigate the role of transpiration in the accumulation of As from the aspects of transpiration regulation and ecotypic difference. Results showed that As accumulation of $P$. vittata increased proportionally with an increase in the As exposure concentration. Lowering the transpiration rate by $28 \sim 67 \%$ decreased the shoot As concentration by 19 56\%. Comparison of As distribution under normal treatment and shade treatment indicated that transpiration determines the distribution pattern of As in pinnae. In terms of the ecotypic difference, the $P$. vittata ecotype from moister and warmer habitat had $40 \%$ higher transpiration and correspondingly $40 \%$ higher shoot As concentration than the ecotype from drier and cooler habitat. Results disclosed that transpiration is the main driver for $P$. vittata to accumulate and redistribute As in pinnae.
\end{abstract}

Keywords Arsenic $\cdot$ Ecotype $\cdot$ Phytoextraction $\cdot$ Pteris vittata $\mathrm{L}$. · Transpiration

\section{Introduction}

Phytoremediation is an attractive technology treating arsenic (As)-contaminated soils because it is low cost, easy to operate,

Responsible editor: Elena Maestri

Mei Lei

leim@igsnrr.ac.cn

1 Institute of Geographic Sciences and Natural Resources Research, Chinese Academy of Sciences, Beijing 100101, China and favorable to landscape. Pteris vittata L. is a known hyperaccumulator with high As concentration and large biomass (Chen et al. 2002; Ma et al. 2001), which has been successfully applied to 200 ha of contaminated soil in China. Recently, the possibility of using $P$. vittata to remediate As-contaminated water has been proposed and verified (Guo et al. 2012; Zhao and Guo 2013). A better understanding of the ecophysiological mechanisms of $P$. vittata to accumulate As would favor the efficient utilization of this species for environment remediation.

It has been found that the cytoplasmic supernatant of $P$. vittata's pinnae is the major place storing As taken up from growth media, reaching up to $60 \%$ of total As in the whole seedling (Chen et al. 2005). The particularly efficient translocation is one of the most important processes in the accumulation of As by P. vittata (Poynton et al. 2004; Su et al. 2008). Mineral ions enter into the xylem of plant roots by apoplastic method or symplastic method and then are generally transported upward driven by transpiration (Hinsinger 1998; Russell and Shorrocks 1959). Whether hyperaccumulators use the same way to largely transport trace elements is not clear yet.

Root-to-shoot translocation of cadmium (Cd) generally occurred via the xylem and is driven by transpiration from the leaves; however, for the Cd hyperaccumulator Sedum alfredii, transpiration played a very limited role (Lu et al. 2009). Similar phenomenon was found for the nickel (Ni) hyperaccumulator Leptoplax emarginata (Bartoli et al. 2012). In contrast, a significantly positive relationship is observed between the shoot $\mathrm{Cd}$ concentration and the transpiration of Phytolacca americana (Liu et al. 2010). And, in several hyperaccumulators, transpiration was found to be the main translocation way of aluminum $(\mathrm{Al})$ and lead $(\mathrm{Pb})$. Lowering the transpiration rate of the Al hyperaccumulator Fagopyrum esculentum Moench by $75 \%$ significantly decreased the aboveground Al concentration (Shen and $\mathrm{Ma}$ 
2001). Increasing transpiration enabled Indian mustard to take up twofold more $\mathrm{Pb}$ (Salt et al. 1995). Such difference in the soil-plant transfer may result both from the variation in elements and the difference in plant species (Basta et al. 2005).

Until now, there has been no direct study on the interaction between As accumulation and transpiration in As hyperaccumulators, whereas several studies have implied the potential relationship between As accumulation and transpiration. In contrast to plants with low tolerance to As that often reduce water uptake when confronting heavy metal stress (Kholodova et al. 2011; Vernay et al. 2007), the As hyperaccumulator $P$. cretica has been reported to increase water uptake under As stress (Lee and Lee 2011). A recent study found that the translocation of As in P. vittata involves three steps: (1) the movement of $\mathrm{As}(\mathrm{V})$ (prevailing species in the rhizosphere) using the phosphorus pathway from the epidermis to the endodermis, (2) the reduction of $\mathrm{As}(\mathrm{V})$ to $\mathrm{As}(\mathrm{III})$ in the endodermis, and (3) the later transport of As(III) via a passive and more efficient process, likely related to water uptake (Lei et al. 2012).

We propose that, unlike the $\mathrm{Ni}$ hyperaccumulator L. emarginata (Bartoli et al. 2012) or Cd hyperaccumulator $S$. alfredii, for the As hyperaccumulator $P$. vittata with its large biomass ( $\sim 9 \mathrm{t}$ dry weight $\mathrm{h} \mathrm{m}^{-2}$ year $^{-1}$ ), transpiration is the main upward translocation process for As after the reduction of As $(\mathrm{V})$ to As(III). This study aims to verify this hypothesis by investigating the role of transpiration in the As hyperaccumulation. The As accumulation pattern in $P$. vittata's fronds under different As exposure concentrations and transpiration-altering treatments was studied. In addition, $P$. vittata has a wide distribution in China, which enables the evolution of ecotypes under diverse habitats. These ecotypes may have different water use efficiency values (Wan et al. 2013), presenting appropriate materials for research on the relationship between transpiration and As accumulation. The responses to transpiration regulation methods of two $P$. vittata ecotypes from habitats with different climatic conditions were further investigated, disclosing the relationship between water metabolism and As accumulation in the hyperaccumulator $P$. vittata.

\section{Materials and methods}

\section{Plant culture}

Spores of $P$. vittata were sown on clean and humid soils, covered by cling film, and placed in a greenhouse with $16 \mathrm{~h}$ of light at an intensity of $300 \mathrm{mE} \mathrm{m}^{-2} \mathrm{~s}^{-1}$, day/night temperatures of $26 / 15^{\circ} \mathrm{C}$, and average relative humidity of $50 \%$. Seedlings with the uniform height of $\sim 20 \mathrm{~cm}$ were transplanted to a modified Hoagland nutrient solution containing $7.5 \times 10^{-4} \mathrm{M} \mathrm{K}_{2} \mathrm{SO}_{4}, 6.5 \times 10^{-4} \mathrm{M} \mathrm{MgSO}_{4}, 0.25 \times 10^{-4} \mathrm{M}$ $\mathrm{KCl}, 0.5 \times 10^{-3} \mathrm{M} \mathrm{Ca}\left(\mathrm{NO}_{3}\right)_{2}, 0.625 \times 10^{-4} \mathrm{M} \mathrm{KH}_{2} \mathrm{PO}_{4}, 0.25 \times$
$10^{-5} \mathrm{M} \mathrm{H}_{3} \mathrm{BO}_{3}, 0.25 \times 10^{-6} \mathrm{M} \mathrm{MnSO}_{4}, 1 \times 10^{-7} \mathrm{M} \mathrm{CuSO}_{4}, 1 \times$ $10^{-6} \mathrm{M} \mathrm{ZnSO}_{4}, 1.25 \times 10^{-9} \mathrm{M}\left(\mathrm{NH}_{4}\right)_{6} \mathrm{MoO}_{4}$, and $0.25 \times$ $10^{-4} \mathrm{M}$ Fe-EDTA (pH adjusted to $\sim 6.2$ ). Chemicals used in the nutrient solution were of analytical grade (Sinopharm Chemical Reagent, Beijing, China).

\section{Experiment 1: effects of As concentrations and shade on the transpiration and As accumulation}

Young seedlings that propagated from spores collected from a greenhouse in Beijing were exposed for 7 days to $0,5,10,20$, or $40 \mathrm{mg} \mathrm{L}^{-1}$ As in form of $\mathrm{Na}_{2} \mathrm{HAsO}_{4} \cdot 7 \mathrm{H}_{2} \mathrm{O}$. The control was provided with a daily photoperiod of $16 \mathrm{~h}$. Shade treatment was provided with a daily photoperiod of $2 \mathrm{~h}$, with other conditions kept the same as the control.

Water loss was recorded by weighing hydroponic bottles and plants every day. Control bottles without plants were treated identically to account for water loss due to evaporation. The transpiration rate was calculated by dividing the daily water loss due to plant transpiration by fresh weight of plant shoots.

At the end of experiment, plants were harvested, washed by running tap water followed by deionized water and oven-dried at $60{ }^{\circ} \mathrm{C}$ for the later analysis of As concentration.

\section{Experiment 2: micro-distribution of As in Pteris vittata under transpiration adjustments}

Precultured $P$. vittata seedlings, as described in "Experiment 1: effects of As concentrations and shade on the transpiration and As accumulation", were transplanted to culture solution containing $5 \mathrm{mg} \mathrm{L}^{-1}$ As in the form of $\mathrm{Na}_{2} \mathrm{HAsO}_{4} \cdot 7 \mathrm{H}_{2} \mathrm{O}$. Pinnae in the middle of mature fronds which no longer sprouted new pinna were chosen for the experiment. One side of the selected pinna was covered by aluminum foil with some perforations underneath to allow respiration (designated as the shade treatment), whereas pinna on the other side was maintained at normal light period (designated as the control).

One day later, $P$. vittata was removed from the culture solution, rinsed with deionized water, and then freeze-dried for synchrotron radiation X-ray fluorescence spectroscopy (SRXRF) analysis. SRXRF scanning was performed at an X-ray micro-beam station at Beamline 4W1B of the Beijing Synchrotron Radiation Facility. The electron storage ring was operated at $2.2 \mathrm{GeV}$ with the current ranging between 59 and $114 \mathrm{~mA}$. Detailed procedures for the measurement and analysis are given by Lei et al. (2012).

\section{Experiment 3: As accumulation of two ecotypes under transpiration regulation}

Spores of two P. vittata ecotypes were collected from Hunan Province (HN) and Guangdong Province (GD). The climates of the sampling sites are described in Table 1. Young seedlings 
Table 1 Climates of the original habitats of two $P$. vittata ecotypes

\begin{tabular}{lll}
\hline & GD & HN \\
\hline Annual average temperature $\left({ }^{\circ} \mathrm{C}\right)$ & 22 & 17 \\
Annual precipitation $(\mathrm{mm})$ & 1736 & 1426 \\
Annual sunshine duration $(\mathrm{h})$ & 1906 & 1174 \\
Annual evaporation $(\mathrm{mm})$ & 1526 & 1124 \\
\hline
\end{tabular}

GD and $\mathrm{HN}$ indicate the Guangdong and Hunan ecotype of $P$. vittata

that propagated from these two spores were transferred to transpiration inhibition or enhancement treatments.

The transpiration inhibition treatment was mimicked by alternative split-root osmotic stress (Dodd et al. 2007; Hu et al. 2006), which can decrease transpiration but keep photosynthetic efficiency as our preliminary experiments showed. Half of the roots were immersed in a normal nutrient solution, while the other half were exposed to a culture solution containing 10 and $20 \%$ polyethylene glycol (PEG) 6000, designated as PEG10 and PEG20 hereafter, respectively. The osmotic potentials of PEG10 and PEG20-added solution were calculated as -0.148 and $-0.491 \mathrm{MPa}$, respectively (Michel and Kaufmann 1973; Money 1989). Twelve hours later, roots in the PEG-added solution were washed with deionized water and transferred to the normal nutrient solution and roots in the normal solution were transferred to the PEG-added solution. This cycle was repeated every $12 \mathrm{~h}$. The transpiration enhancement treatment was created by adding $1-4 \mathrm{mM} \mathrm{KNO}_{3}$ to the culture solution, designated as $\mathrm{K} 1$ to $\mathrm{K} 4$ hereafter. Plants of control were kept in the normal nutrient solution. Each treatment has four replicates. As concentration in the culture solution was kept at $1 \mathrm{mg} \mathrm{L}^{-1}$.

Transpiration measurement During the experimental period, three pinnae in the middle of mature fronds which no longer sprouted new pinna were chosen for the measurement of transpiration rate. Li-6400 portable photosynthesis system (LI-COR, USA) was used to measure the transpiration rate at maximum sunlight conditions from 11:00 to 13:00. The daily water loss due to plant transpiration was also recorded.

Ten days after the treatment, fresh pinnae were collected and immediately measured with an environmental scanning electron microscope fitted with energy dispersive X-ray for the stomatal size, stomatal aperture, and relative potassium (K) content of guard cells. Details of the analysis method are given by Li et al. (2005). Each measurement had 10 replicates. The rest of the plant samples were collected, washed, and oven-dried at $60{ }^{\circ} \mathrm{C}$ for the later analysis of As concentration.

\section{Chemical analysis and data process}

Chemical analysis Oven-dried plant samples were finely ground and digested with a mixture of $\mathrm{HNO}_{3}$ and $\mathrm{HClO}_{4}(v /$ $v=10: 1$ ) and analyzed for As concentration (Hydride Generation Atomic Fluorescence Spectrometer, Haiguang AFS-2002). The quality control of the digestion and analysis was verified using certified reference material (GSV-2) from the National Standard Materials Center. The recovery rate of As was $90.9-109.1 \%$.

Data process The translocation index was defined as the ratio of the root-to-shoot As concentration. A two-factor ANOVA, ecotype $\times$ transpiration-altering treatments, was performed to analyze differences in transpiration rates and As concentrations of $\mathrm{HN}$ and GD ecotypes. ANOVA and linear regression were performed using SPSS statistical program package (SPSS, Inc., Chicago, USA., Release 13.0). The significance level was set at an error probability of 0.05 .

\section{Results}

\section{Effects of As concentrations and shade on the transpiration and As accumulation}

Experiment 1 showed that the supplied As concentrations and shade treatment significantly influenced the transpiration and As accumulation of $P$. vittata.

Under normal light condition, the transpiration rate of $P$. vittata increased when exposed to low concentrations of As $\left(5\right.$ and $\left.10 \mathrm{mg} \mathrm{L}^{-1}\right)$ in comparison to the As-free solution $(P<0.05$, Fig. 1a). When exposed to high concentrations of As ( 20 and $40 \mathrm{mg} \mathrm{L}^{-1}$ ), the transpiration rate of $P$. vittata decreased, indicating that high As concentration in the nutrient solution may injure the normal physiological activities of $P$. vittata. Shade decreased the transpiration rate of $P$. vittata by $56,67,32$, and $28 \%$ in the $5,10,20$, and $40 \mathrm{mg} \mathrm{L}^{-1} \mathrm{As}$ treatment, respectively.

Under both normal light condition and shade treatment, the shoot As concentrations of $P$. vittata increased with an increase in the exposure As concentration (Fig. 1b). There was a linear relationship between As in nutrient solution and As in $P$. vittata shoots when As in the nutrient solution was lower than $10 \mathrm{mg} \mathrm{L}^{-1}$ As. Shade treatment decreased shoot As concentrations of $P$. vittata by $47,56,51$, and $45 \%$ in the 5,10 , 20 , and $40 \mathrm{mg} \mathrm{L}^{-1}$ As treatment, respectively.

\section{Distribution of As in fronds in light and dark}

Using SRXRF, experiment 2 studied the micro-distribution patterns of As under transpiration adjustments. Provided with normal light, As contents decreased from vein to edge (Fig. 2). As concentration at pinna edge was $1 / 2$ of that at the pinna vein, posing a positive As gradient, which may favor the transfer of As from vein to edge. Shade treatment, which decreased the water loss of $P$. vittata by $\sim 50 \%$ (data not 

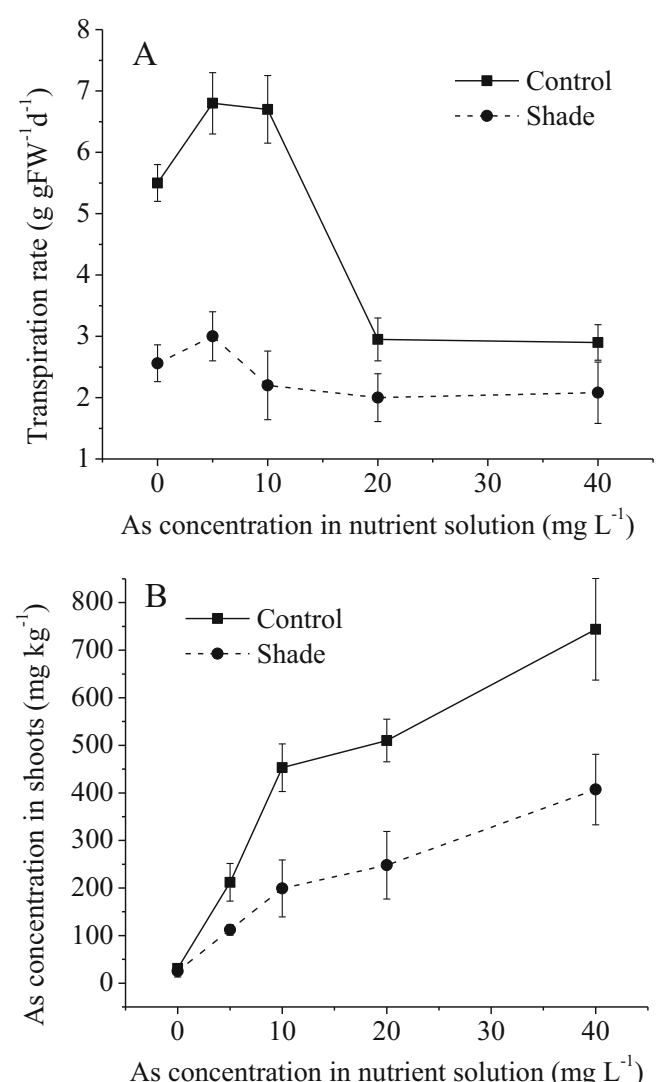

Fig. 1 Effects of As concentrations and shade on transpiration (a) and As accumulation (b) of $P$. vittata

provided), noticeably decreased As content at all the six scanning sites, with the largest decrease occurring at the edge ( $\sim 89 \%)$. The positive gradient of As from vein to edge was less obvious in the shaded treatment. Results indicated that inhibiting transpiration partly blocked the loading of As from vein to edge of $P$. vittata's pinnae, implying the role of transpiration in determining the distribution of As in pinnae.

\section{Relationship between transpiration and As accumulation in two $P$. vittata ecotypes}

Morphological characteristics The rhizoid/frond biomass ratio of the GD ecotype from moister and warmer habitat was significantly lower than that of the $\mathrm{HN}$ ecotype from dryer and cooler habitat $(P<0.05$, Table 2$)$. The GD ecotype had higher pinnae density and larger leaf area per unit dry weight than the HN ecotype. The GD ecotype also had $9.4 \%$ higher stomatal density and $55 \%$ larger average stomatal size than the HN ecotype. Differences in morphological characteristics between the GD and HN ecotype indicated that under varied climatic conditions, $P$. vittata can develop into ecotypes with different pinnae and rhizoid characteristics, contributing to their difference in transpiration.

Transpiration rate Both ecotype and transpiration-altering treatments led to significant differences in the transpiration of $P$. vittata, and the interaction between ecotype and transpiration treatments also contributed to the difference in transpiration rates (two-way ANOVA analysis, $P<0.05$ ).

The alternative split-root osmotic stress caused by PEG decreased the transpiration of both ecotypes (Fig. 3). PEG10 led to a 20 and $18 \%$ decrease in transpiration rates of the GD and $\mathrm{HN}$ ecotype, respectively. PEG20 caused more obvious impacts: 64 and $42 \%$ decrease in transpiration rates of the GD and $\mathrm{HN}$ ecotype, respectively.

Results indicated that the transpiration enhancement method, adding $\mathrm{K}$, could increase the transpiration rate. With an increase in the added $\mathrm{K}$ concentration, transpiration displayed a slight increase. The $\mathrm{K} 4$ treatment increased the transpiration rates of the GD and $\mathrm{HN}$ ecotype by 23 and $56 \%$, respectively. In agreement with the change in transpiration rate, the addition of K obviously increased $\mathrm{K}$ content in the guard cells of both ecotypes $(P<0.05$, Fig. 4$)$. There existed significantly positive correlation between $\mathrm{K}$ concentrations of guard cells and
Fig. 2 Effect of shade on As distribution in pinnae. As count indicates the normalized fluorescence intensity, indicating the As concentration

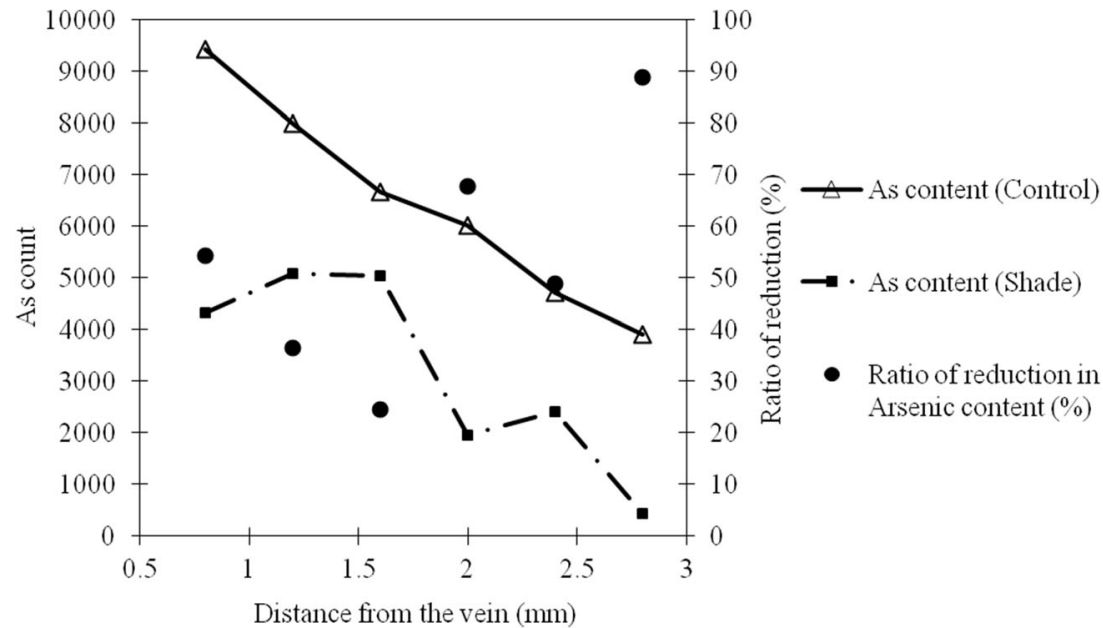


Table 2 The morphological characteristics of two ecotypes

\begin{tabular}{lll}
\hline Ecotype & GD & HN \\
\hline Rhizoid/frond biomass ratio & $0.18 \pm 0.01 \mathrm{~b}$ & $0.22 \pm 0.03 \mathrm{a}$ \\
Pinna density & $1.52 \pm 0.13 \mathrm{a}$ & $1.33 \pm 0.08 \mathrm{a}$ \\
Pinna area/unit dry weight $\left(\mathrm{m}^{2} \mathrm{~g}^{-1}\right)$ & $0.33 \pm 0.24 \mathrm{a}$ & $0.22 \pm 0.03 \mathrm{a}$ \\
Stoma density $\left(\mathrm{mm}^{-2}\right)$ & $58.4 \pm 11.8 \mathrm{a}$ & $53.4 \pm 4.7 \mathrm{a}$ \\
Average stoma size $\left(\mu \mathrm{m}^{2}\right)$ & $46.5 \pm 7.7 \mathrm{a}$ & $30.0 \pm 5.9 \mathrm{~b}$ \\
\hline
\end{tabular}

GD and $\mathrm{HN}$ indicate the Guangdong and Hunan ecotype of $P$. vittata. Pinna density $=$ number of pinnae/length of frond. Values are means \pm SD. Values with different letters within rows indicate significant differences between two ecotypes $(P<0.05, n=4$ for the rhizoid/frond biomass ratio and for the rest $P<0.05, n=10)$.

transpiration rates $(P<0.05)$, indicating that $\mathrm{K}$ increased transpiration rate by improving the $\mathrm{K}$ concentration of guard cells.

The GD ecotype exhibited higher transpiration rates than the HN ecotype in all these treatments except PEG20, in accordance with the habitat climates and the morphological characteristics of these two ecotypes (Tables 1 and 2). The difference between two ecotypes was significant in all these treatments except K4 $(P<0.05)$. Comparing the responses of two ecotypes to transpiration regulation methods, it was found that split-root osmotic stress reduced the transpiration of the GD ecotype to a larger extent.

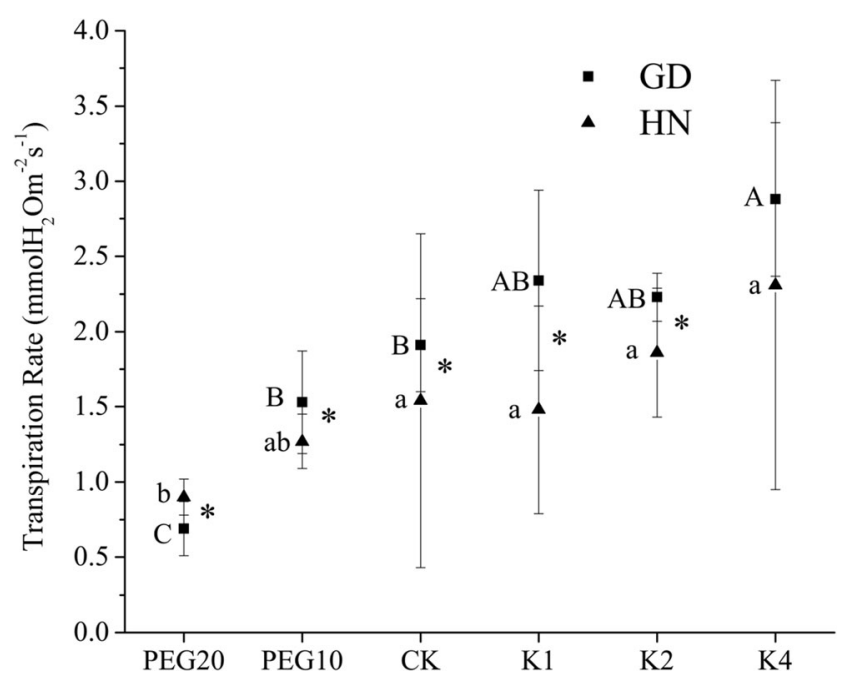

Fig. 3 Transpiration rates of two $P$. vittata ecotypes under transpiration regulation. GD and $\mathrm{HN}$ indicate the Guangdong and Hunan ecotype of $P$. vittata. Different capital letters beside the error bar indicate significant difference among treatments for the GD ecotype. Different lowercase letters beside the error bar indicate significant difference among treatments for the $\mathrm{HN}$ ecotype. Asterisks indicate significant differences between ecotypes $(P<0.05, n=4)$. CK is the control with $P$. vittata growing in the normal culture solution. PEG10 and PEG20 indicate the transpiration-decreasing treatments, created by adding 10 and $20 \%$ polyethylene glycol 6000 to the culture solution, respectively. K1-K4 indicate the transpiration enhancement treatments, created by adding 1$4 \mathrm{mM} \mathrm{KNO}_{3}$ to the culture solution

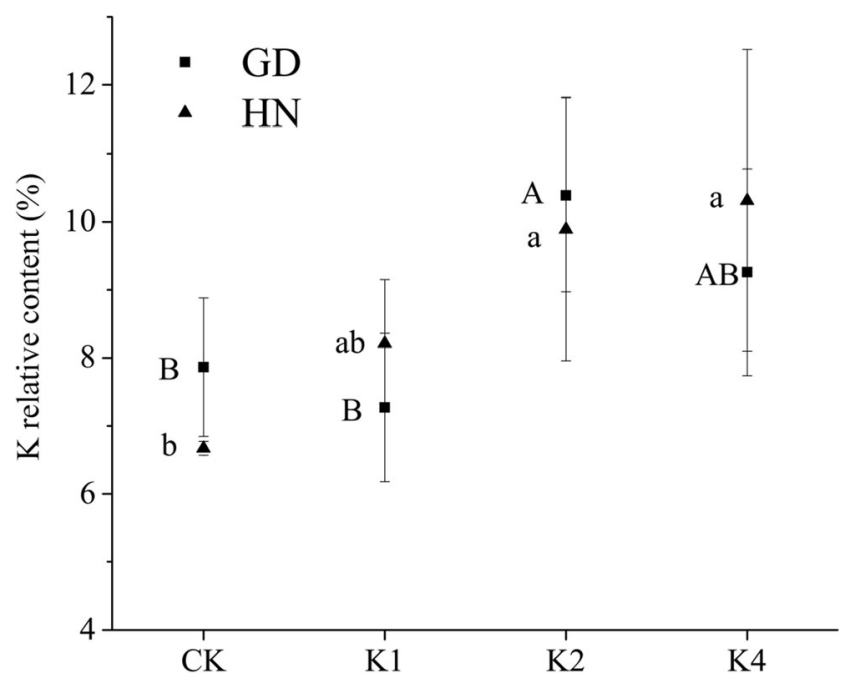

Fig. 4 Relative content of potassium in guard cells of two P. vittata ecotypes. GD and HN indicate the Guangdong and Hunan ecotype of P. vittata. Different capital letters beside the error bar indicate significant difference among treatments for the GD ecotype. Different lowercase letters beside the error bar indicate significant difference among treatments for the $\mathrm{HN}$ ecotype $(P<0.05, n=4)$. CK is the control with $P$. vittata growing in the normal culture solution. $\mathrm{K} 1-\mathrm{K} 4$ indicate the transpiration enhancement treatments, created by adding $1-4 \mathrm{mM} \mathrm{KNO}_{3}$ to the culture solution

As accumulation Arsenic accumulation in both ecotypes obviously decreased under split-root osmotic stress and increased with the addition of $\mathrm{K}$ (Table 3). Both ecotypic variation and transpiration regulation led to a significant difference in As accumulation of $P$. vittata, and the interaction effect of ecotype and transpiration regulation methods also contributed $(P<0.05)$.

In accordance with the decreased transpiration rates, shoot As concentrations of the GD ecotype under PEG10 and PEG20 treatments decreased by $\sim 68$ and $\sim 80 \%$ in comparison to the control, respectively. The HN ecotype displayed a less obvious decrease in shoot As concentration: 55 and $60 \%$ under the treatment of PEG10 and PEG20, respectively. PEG treatments displayed no obvious impacts on the root As concentration of the GD ecotype but decreased the root As concentration of the HN ecotype. PEG treatments greatly decreased the translocation index of the GD ecotype, being 1/ 4 of the control. The decrease in translocation index of the HN ecotype under split-root osmotic stress was less obvious.

The enhancement of transpiration by adding K slightly increased the shoot As concentration of the GD ecotype, with a similar trend with transpiration rates. The K4 treatment of the GD ecotype had a $72.5 \%$ higher translocation index than the control $(P<0.05)$. The HN ecotype displayed a more obvious increase. The $\mathrm{K} 4$ treatment led to an $85 \%$ increase in As concentration and $210 \%$ increase in As translocation index $(P<0.05)$. Potassium had no obvious effect on the root As concentration of the GD ecotype but slightly increased the root As concentrations of the $\mathrm{HN}$ ecotype (Table 3). 
Table 3 As accumulation of two $P$. vittata ecotypes under transpiration alteration treatments

\begin{tabular}{|c|c|c|c|c|}
\hline Ecotype & Treatment & As in shoot $\left(\mathrm{mg} \mathrm{kg}^{-1}\right)$ & As in root $\left(\mathrm{mg} \mathrm{kg}^{-1}\right)$ & Translocation index \\
\hline \multirow[t]{6}{*}{ GD } & PEG20 & $558.8 \pm 174.5 b$ & $683.9 \pm 85.9 \mathrm{a}$ & $0.81 \pm 0.17 \mathrm{c}$ \\
\hline & PEG10 & $887.6 \pm 257.1 \mathrm{~b}$ & $779.4 \pm 51.9 a^{*}$ & $1.13 \pm 0.27 \mathrm{c}$ \\
\hline & $\mathrm{CK}$ & $2768 \pm 258 a^{*}$ & $703 \pm 99 a$ & $4.0 \pm 0.6 b^{*}$ \\
\hline & K1 & $3327 \pm 409 \mathrm{a}^{*}$ & $922 \pm 218 a^{*}$ & $3.8 \pm 1.1 \mathrm{~b}$ \\
\hline & K2 & $2953 \pm 192 a^{*}$ & $699 \pm 56 a^{*}$ & $4.3 \pm 0.6 b$ \\
\hline & K4 & $3054 \pm 276 a$ & $527 \pm 276 a$ & $6.9 \pm 3.0 \mathrm{a}$ \\
\hline \multirow[t]{6}{*}{$\mathrm{HN}$} & PEG20 & $756.3 \pm 261.2 \mathrm{c}$ & $610.9 \pm 70.6 b$ & $1.22 \pm 0.3 b$ \\
\hline & PEG10 & $836.3 \pm 229.1 \mathrm{c}$ & $470.9 \pm 189.6 b$ & $1.86 \pm 0.44 \mathrm{~b}$ \\
\hline & $\mathrm{CK}$ & $1952 \pm 148 b$ & $842 \pm 359 a$ & $1.9 \pm 0.7 \mathrm{~b}$ \\
\hline & $\mathrm{K} 1$ & $1974 \pm 98 b$ & $435 \pm 78 b$ & $4.4 \pm 0.5 \mathrm{a}$ \\
\hline & $\mathrm{K} 2$ & $2064 \pm 160 b$ & $431 \pm 20 b$ & $4.8 \pm 0.2 \mathrm{a}$ \\
\hline & $\mathrm{K} 4$ & $3615 \pm 1858 \mathrm{a}$ & $608 \pm 282 \mathrm{ab}$ & $5.9 \pm 0.9 \mathrm{a}$ \\
\hline
\end{tabular}

GD and HN indicate the Guangdong and Hunan ecotype of $P$. vittata. CK is the control with $P$. vittata growing in the normal culture solution. PEG10 and PEG20 indicate the transpiration-decreasing treatments, created by adding 10 and $20 \%$ polyethylene glycol 6000 to the culture solution, respectively. $\mathrm{K} 1-\mathrm{K} 4$ indicate the transpiration enhancement treatments, created by adding $1-4 \mathrm{mM} \mathrm{KNO}_{3}$ to the culture solution. Values are means $\pm \mathrm{SD}$. Values with different letters within columns indicate significant differences between various treatments at $P<0.05(n=4)$. Asterisks indicate significant difference between two ecotypes at $P<0.05(n=4)$

Comparing these two ecotypes, the shoot As concentrations of the GD ecotype were higher than those of the HN ecotype in most treatments except PEG10 and K4 treatment. The GD ecotype displayed a greater decrease in As accumulation under the inhibition of transpiration but a smaller increase in the transpiration enhancement treatments than the $\mathrm{HN}$ ecotype.

Relationship between transpiration and As accumulation To better evaluate the contribution of transpiration to As accumulation in P. vittata, a comparison between the measured As amount and the implied As amount calculated from transpiration (obtained by multiplying the water loss and the As concentration in the culture solution) was conducted. The predicated As accounted for more than half of the measured As amount (Fig. 5). Transpiration accounted for $\sim 74$ and $\sim 50 \%$ of the As accumulated by the GD and HN ecotype, respectively.

$\mathrm{K}$ obviously increased the contribution of transpiration to As accumulation in the HN ecotype. Transpiration accounted for $\sim 80 \%$ of As accumulated by the HN ecotype in the K1 treatment. The GD ecotype showed a less obvious increase in the contribution of transpiration in the $\mathrm{K}$ treatment, in accordance with the change in the shoot As concentration.

\section{Discussions}

Contribution of transpiration to As accumulation of $P$. vittata The current study indicates that transpiration made a notable contribution to As accumulation by $P$. vittata, based on the observation that (a) with an increase in the exposure concentration of As, the shoot As concentration of $P$. vittata increased proportionally, (b) inhibition of transpiration decreased As concentrations in shoots, while improving transpiration increased As concentrations in shoots, and (c) the $P$. vittata ecotype with higher transpiration rate accumulated more As in the aboveground parts than that with lower transpiration rate.

Lei et al. (2012) suggested that before entering into the endodermis of $P$. vittata rhizoids, As utilizes the phosphate pathway, while after that, phosphate pathway no longer works for As, which means that the transport of As after the endodermis requires another carrier. Based on results from the present study, this carrier may be closely related to water uptake. The earlier view is that water molecules enter into cells through passive diffusion, but recently, it has been suggested that some specialized water transport carriers like aquaglyceroporins play an important role (Luu and Maurel 2005; Preston et al. 1992). The aquaglyceroporins, a class of water channel not only permeable to water molecules but also permeable to glycerol and small solutes (Thomas et al. 2002), have been identified as carriers of As in bacteria, yeast, humans, and other vertebrates (Mukhopadhyay et al. 2014) but not found in the As hyperaccumulator yet (Mathews et al. 2011). Either through passive diffusion or aquaglyceroporin-aided transport, the As translocation in $P$. vittata is found to be closely related to water uptake.

In addition, suppression of transpiration obviously decreased As concentration at the edge of $P$. vittata pinnae, implying the role of transpiration in As accumulation and distribution in $P$. vittata. Inhibiting transpiration blocked the movement of As from vein to epidermis, indicating that the lack of enough transpiration as a driving force disabled the transfer of 

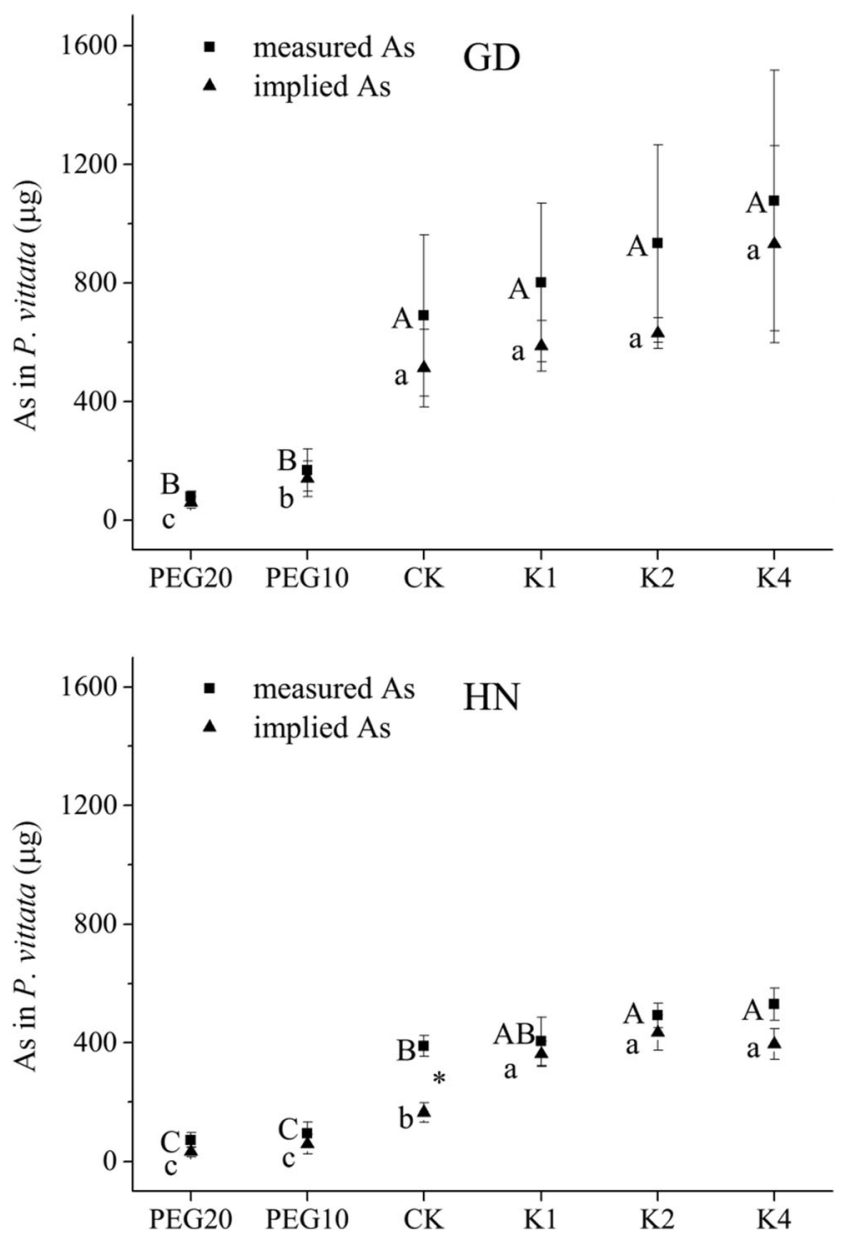

Fig. 5 The measured and implied As amount. Measured As amount= shoot As concentration of $P$. vittata $\times$ shoot biomass. Implied As amount $=$ As concentration of the culture solution $\times$ water loss. GD and $\mathrm{HN}$ indicate the Guangdong and Hunan ecotype of $P$. vittata. CK is the control with $P$. vittata growing in the normal culture solution. PEG10 and PEG20 indicate the transpiration-decreasing treatments, created by adding 10 and $20 \%$ polyethylene glycol 6000 to the culture solution, respectively. $\mathrm{K} 1-\mathrm{K} 4$ indicate the transpiration enhancement treatments, created by adding 1-4 $\mathrm{mM} \mathrm{KNO}_{3}$ to the culture solution. Different capital letters beside the error bar indicate significant difference among treatments for the measured As amount. Different lowercase letters beside the error bar indicate significant difference among treatments for the implied As amount. Asterisks indicate significant differences between measured As and calculated As in $P$. vittata $(P<0.05, n=4)$

As from vein to epidermis, which is one of the main places where As accumulates in $P$. vittata.

\section{Evolutionary theory behind the relationship between tran-} spiration and As accumulation The $P$. vittata ecotype with higher transpiration rate displayed correspondingly morphological characteristics, including higher pinna density, larger leaves, and more stomata, indicating that the difference in transpiration rates has become a heritable trait of this ecotype.

Studies have found that plants growing under different climatic conditions can adapt to local climate and evolve genetically stable variation in morphological and physiological characteristics (Abd El Rahman and Krzywinski 2008; Zhang et al. 2005). An extreme example is certain plant species in arid regions showing correspondingly small and thick leaves and extremely low transpiration rates (Ma et al. 2008). Such morphological and physiological adaptation of plant ecotypes to local environment has been also found in hyperaccumulators, such as $\mathrm{Zn}$ hyperaccumulator $S$. alfredii (Yang et al. 2010) and $\mathrm{Pb} / \mathrm{Cd} /$ thallium (T1) cohyperaccumulator Biscutella laevigata (Wierzbicka and Pielichowska 2004) s.

In this study, the GD ecotype from a habitat with higher temperature, precipitation, and evaporation exhibited higher transpiration rates and the corresponding morphological characteristics. The adaptation of leaf structure, morphologically or histologically, often reflects clearly the effect of environmental stress and therefore is often used as an index evaluating the impacts of environmental conditions on plants (Dinis et al. 2011; Souto et al. 2009). The significant interactive effect of ecotype and transpiration regulation $(P<0.05)$ indicated that different ecotypes had varying responses to transpirationaltering measures. To adapt to local climatic conditions, $P$. vittata can evolve constitutive and hereditary traits in these ecotypes, resulting in different transpiration rates, which led to a difference in As accumulation.

From the evolutionary perspective, it is considered that the appearance of heavy metal tolerance is the result of long-term exposure to high metal concentration in the growth media (Lombi et al. 2000). But, how did a small group of plants evolve the heavy metal hyperaccumulation is still unclear. In this study, it is found that under different climatic conditions, $P$. vittata formed varied water uptake mechanisms, which contributed to different As accumulation capacities.

The hyperaccumulation of certain metals may be important in the osmotic adjustment of plants under water stress, based on the discovery that the nickel $(\mathrm{Ni})$ hyperaccumulation in Stackhousia tryonii is a trait protecting the plant from drought in serpentine soils, with $\mathrm{Ni}$ acting as an osmoregulatory agent (Bhatia et al. 2005). Arsenic is closely related to the water consumption in hyperaccumulators. In the current study, As accumulation and transpiration displayed strong correlation. Higher transpiration due to transpiration regulation or ecotypic difference always led to higher As accumulation by $P$. vittata. And, on the other hand, low As exposure greatly increased the transpiration of $P$. vittata, similar to another As hyperaccumulator Pteris cretica (Lee and Lee 2011). It requires further investigation in that the evolution of As accumulation is related to water stress, similar to the inadvertent uptake theory of hyperaccumulation, which is that hyperaccumulation resulted from inadvertent uptake if the accumulated elements are chemically similar to essential nutrients and plant populations evolve more efficient uptake and translocation systems for these nutrients (Cappa and PilonSmits 2014; Pollard et al. 2014; Verbruggen et al. 2009). 
However, studies on different but related physiological processes in different ecotypes of one species may provide essential information for the further dissection of genetics study of these traits.

\section{Conclusion}

This study disclosed the positive correlation between transpiration and As accumulation in As hyperaccumulator $P$. vittata by comparing As concentration in two $P$. vittata ecotypes from habitats with diverse climatic conditions. Transpiration is the main driver for $P$. vittata to accumulate and re-distribute As in pinnae. It is suggested that $P$. vittata ecotypes may evolve different As accumulation abilities, together with the formation of different water use efficiency, as a result of living in habitats with diverse climatic conditions.

Acknowledgments We thank Dr. Augustine Doronila from the University of Melbourne for improving the manuscript. Financial support was provided by the National Natural Science Foundation of China (Grant Nos. 41301547), the Program for "Bingwei" Excellent Talents in the Institute of Geographic Sciences and Natural Resources Research, CAS, and the special fund for environment protection research in the public interest (No. 201409044).

\section{References}

Abd El Rahman HF, Krzywinski K (2008) Environmental effects on morphology of Acacia tortilis group in the Red Sea Hills, NorthEastern Sudan and South-Eastern Egypt. For Ecol Manag 255:254263

Bartoli F, Coinchelin D, Robin C, Echevarria G (2012) Impact of active transport and transpiration on nickel and cadmium accumulation in the leaves of the Ni-hyperaccumulator Leptoplax emarginata: a biophysical approach. Plant Soil 350:99-115

Basta NT, Ryan JA, Chaney RL (2005) Trace element chemistry in residual-treated soil: key concepts and metal bioavailability. J Environ Qual 34:49-63

Bhatia NP, Baker AJM, Walsh KB, Midmore DJ (2005) A role for nickel in osmotic adjustment in drought-stressed plants of the nickel hyperaccumulator Stackhousia tryonii Bailey. Planta 223:134-139

Cappa JJ, Pilon-Smits EAH (2014) Evolutionary aspects of elemental hyperaccumulation. Planta 239:267-275

Chen TB, Wei CY, Huang ZC, Huang QF, Lu QG, Fan ZL (2002) Arsenic hyperaccumulator Pteris vittata L. and its arsenic accumulation. Chin Sci Bull 47:902-905

Chen TB, Yan XL, Liao XY, Xiao XY, Huang ZC, Xie H, Zhai LM (2005) Subcellular distribution and compartmentalization of arsenic in Pteris vittata L. Chin Sci Bull 50:2843-2849

Dinis LT, Peixoto F, Pinto T, Costa R, Bennett RN, Gomes-Laranjo J (2011) Study of morphological and phenological diversity in chestnut trees ('Judia' variety) as a function of temperature sum. Environ Exp Bot 70:110-120

Dodd I, Davies W, Egea G (2007) Transport of growth regulators from roots in drying soil during partial rootzone drying: the mechanics of a new deficit irrigation technique. Comp Biochem Phys A 146: S239-S239
Guo HM, Zhong ZN, Lei M, Xue XL, Wan XM, Zhao JY, Chen TB (2012) Arsenic uptake from arsenic-contaminated water using hyperaccumulator Pteris vittata L.: effect of chloride, bicarbonate, and arsenic species. Water Air Soil Pollut 223:4209-4220

Hinsinger, P., 1998. How do plant roots acquire mineral nutrients? Chemical processes involved in the rhizosphere. In: Donald, LS (ed) Advances in agronomy. Academic Press, USA, pp. 225-265.

Hu T, Kang S, Zhang F, Zhang J (2006) Alternate application of osmotic and nitrogen stresses to partial root system: effects on root growth and nitrogen use efficiency. J Plant Nutr 29:2079-2092

Kholodova V, Volkov K, Abdeyeva A, Kuznetsov V (2011) Water status in Mesembryanthemum crystallinum under heavy metal stress. Environ Exp Bot 71:382-389

Lee SJ, Lee JP (2011) Effect of arsenic absorption on the water-refilling speed of Pteris cretica. Microsc Res Tech 74:517-522

Lei M, Wan X-M, Huang Z-C, Chen T-B, Li X-W, Liu Y-R (2012) First evidence on different transportation modes of arsenic and phosphorus in arsenic hyperaccumulator Pteris vittata. Environ Pollut 161:1-7

Li WX, Chen TB, Chen Y, Lei M (2005) Role of trichome of Pteris vittata L. in arsenic hyperaccumulation. Sci China Ser C 48:148-154

Liu XQ, Peng KJ, Wang AG, Lian CL, Shen ZG (2010) Cadmium accumulation and distribution in populations of Phytolacca americana L. and the role of transpiration. Chemosphere 78:1136-1141

Lombi E, Zhao FJ, Dunham SJ, McGrath SP (2000) Cadmium accumulation in populations of Thlaspi caerulescens and Thlaspi goesingense. New Phytol 145:11-20

Lu L-L, Tian S-K, Yang X-E, Li T-Q, He Z-L (2009) Cadmium uptake and xylem loading are active processes in the hyperaccumulator Sedum alfredii. J Plant Physiol 166:579-587

Luu DT, Maurel C (2005) Aquaporins in a challenging environment: molecular gears for adjusting plant water status. Plant Cell Environ 28:85-96

Ma CC, Gao YB, Guo HY, Wang JL, Wu JB, Xu JS (2008) Physiological adaptations of four dominant Caragana species in the desert region of the Inner Mongolia Plateau. J Arid Environ 72:247-254

Ma LQ, Komar KM, Tu C, Zhang W, Cai Y, Kennelley ED (2001) A fern that hyperaccumulates arsenic. Nature 409:579

Mathews S, Rathinasabapathi B, Ma LQ (2011) Uptake and translocation of arsenite by Pteris vittata L.: effects of glycerol, antimonite and silver. Environ Pollut 159:3490-3495

Michel BE, Kaufmann MR (1973) The osmotic potential of polyethylene glycol 6000. Plant Physiol 51:914-916

Money NP (1989) Osmotic pressure of aqueous polyethylene glycols. Plant Physiol 91:766-769

Mukhopadhyay R, Bhattacharjee H, Rosen BP (2014) Aquaglyceroporins: generalized metalloid channels. Biochim Biophys Acta Gen Subj 1840:1583-1591

Pollard AJ, Reeves RD, Baker AJM (2014) Facultative hyperaccumulation of heavy metals and metalloids. Plant Sci 217218:8-17

Poynton CY, Huang JWW, Blaylock MJ, Kochian LV, Elless MP (2004) Mechanisms of arsenic hyperaccumulation in Pteris species: root As influx and translocation. Planta 219:1080-1088

Preston GM, Carroll TP, Guggino WB, Agre P (1992) Appearance of water channels in Xenopus oocytes expressing red-cells CHIP28 protein. Science 256:385-387

Russell RS, Shorrocks VM (1959) The relationship between transpiration and the absorption of inorganic ions by intact plants. J Exp Bot 10: 301-316

Salt DE, Prince RC, Pickering IJ, Raskin I (1995) Mechanisms of cadmium mobility and accumulation in Indian mustard. Plant Physiol 109: $1427-1433$

Shen RF, Ma JF (2001) Distribution and mobility of aluminium in an Alaccumulating plant, Fagopyrum esculentum Moench. J Exp Bot 52: $1683-1687$ 
Souto CP, Premoli AC, Reich PB (2009) Complex bioclimatic and soil gradients shape leaf trait variation in Embothrium coccineum (Proteaceae) among austral forests in Patagonia. Revista Chilena De Historia Nat 82:209-222

Su YH, McGrath SP, Zhu YG, Zhao FJ (2008) Highly efficient xylem transport of arsenite in the arsenic hyperaccumulator Pteris vittata. New Phytol 180:434-441

Thomas D, Bron P, Ranchy G, Duchesne L, Cavalier A, Rolland J-P, Raguénès-Nicol C, Hubert J-F, Haase W, Delamarche C (2002) Aquaglyceroporins, one channel for two molecules. Biochimica et Biophysica Acta (BBA) - Bioenergetics 1555:181-186

Verbruggen N, Hermans C, Schat H (2009) Molecular mechanisms of metal hyperaccumulation in plants. New Phytol 181:759-776

Vernay P, Gauthier-Moussard C, Hitmi A (2007) Interaction of bioaccumulation of heavy metal chromium with water relation, mineral nutrition and photosynthesis in developed leaves of Lolium perenne L. Chemosphere 68:1563-1575

Wan XM, Lei M, Liu YR, Huang ZC, Chen TB, Gao D (2013) A comparison of arsenic accumulation and tolerance among four populations of Pteris vittata from habitats with a gradient of arsenic concentration. Sci Total Environ 442:143-151

Wierzbicka M, Pielichowska M (2004) Adaptation of Biscutella laevigata L, a metal hyperaccumulator, to growth on a zinc-lead waste heap in southern Poland - I: differences between waste-heap and mountain populations. Chemosphere 54:1663-1674

Yang XE, Chao YE, Ye HB, He ZL, Stoffella PJ (2010) Zinc and lead accumulation by two contrasting ecotypes of Sedum alfredii Hance at different zinc/lead complex levels. Commun Soil Sci Plant Anal 41:516-525

Zhang X, Wu N, Li C (2005) Physiological and growth responses of Populus davidiana ecotypes to different soil water contents. J Arid Environ 60:567-579

Zhao JY, Guo HM (2013) Arsenic uptake from arsenic-contaminated water using Pteris vittata L. and Polystichum craspedosorum. In: Tang X, Zhong W, Zhuang D, Li C, Liu Y (eds) Progress in environmental protection and processing of resource, vol 1-4, Pts., pp $1139-1143$ 